\title{
Effect of recombinant bovine granulocyte colony-stimulating factor covalently bound to polyethylene glycol injection on neutrophil number and function in periparturient dairy cows
}

\author{
Kayoko Kimura, ${ }^{*}$ Jesse P. Goff, † Peter Canning, $\ddagger$ Chong Wang,§ and James A. Roth ${ }^{\star 1}$ \\ ${ }^{*}$ Department of Veterinary Microbiology and Preventive Medicine, and \\ †Department of Biomedical Sciences, College of Veterinary Medicine, lowa State University, Ames 50011 \\ ‡Bioproduct Innovation, Elanco Animal Health, Greenfield, IN 46140 \\ §Department of Veterinary Diagnostics and Production Animal Medicine, College of Veterinary Medicine, lowa State University, Ames 50011
}

\section{ABSTRACT}

Dairy cows often experience decreased immune function around the time of calving, typified by impaired polymorphonuclear neutrophil (PMN) function and a transient neutropenia. This is associated with increased disease incidence, including mastitis, retained placenta, and metritis. In an attempt to improve PMN functional capacity during the periparturient period, we injected cows with recombinant bovine granulocyte colonystimulating factor covalently bound to polyethylene glycol (PEG rbG-CSF) twice subcutaneously, about 6 $\mathrm{d}$ before calving and within $24 \mathrm{~h}$ after calving. Twentyone cows in their second pregnancy were enrolled in this study and divided into 2 groups: PEG rbG-CSF treated $(\mathrm{n}=11)$ and saline-treated controls $(\mathrm{n}=10)$. The PMN numbers quickly and dramatically increased after PEG rbG-CSF administration and remained elevated through the end of the experiment (13 d after calving). Exocytosis of myeloperoxidase by stimulated $\mathrm{PMN}$, which is generally decreased in periparturient cows, was markedly increased by PEG rbG-CSF after injection. Higher myeloperoxidase exocytosis persisted for at least $10 \mathrm{~d}$ after calving. The PMN superoxide anion release and phagocytosis activity did not differ between groups. Injection of PEG rbG-CSF was safe for cows, with no significant negative effects observed. The greatest single effect of PEG rbG-CSF administration was a dramatic increase in circulating numbers of PMN. The increased numbers of PMN ready to move to a site of infection early in the course of an infection may improve the ability of the cow to ward off clinical disease in the periparturient period.

Key words: granulocyte-colony stimulating factor, neutrophil, periparturient immunosuppression

Received July 8, 2013.

Accepted April 7, 2014.

${ }^{1}$ Corresponding author: jaroth@iastate.edu

\section{INTRODUCTION}

Dairy cows suffer from decreased immune cell function around the time of calving. Many indices of polymorphonuclear neutrophil (PMN) and lymphocyte functions decrease gradually starting about 2 or 3 wk before calving, with most indices reaching a nadir at the time of calving ( 0 to $2 \mathrm{~d}$ after calving) and then gradually recovering in 2 to 4 wk (Kehrli et al., 1989; Kimura et al., 1999; Kimura et al., 2002). Almost all cows experience decreased immune function during the periparturient period, but in some cows the immune suppression is more pronounced. This periparturient immunosuppression is associated with a high incidence of diseases (both metabolic and infectious; Burton et al., 2001; Kimura et al., 2006). Metritis, retained placenta, and mastitis are diseases known to be associated with decreased PMN function (Waller, 2000; Kimura et al., 2002; Hammon et al., 2006). The reason for decreased PMN function during the periparturient period has been attributed to increased nutrient demand for fetal growth and colostrum production at the end of pregnancy. At the onset of lactation, most cows experience negative energy and protein balance, as well as alterations in mineral and vitamin status (Waller, 2000; Goff et al., 2002; Martinez et al., 2012), which are suspected to contribute to decreased PMN function (Kimura et al., 1999; Kimura et al., 2002; Hammon et al., 2006). Supplementing vitamin E (Politis et al., 1995, 2001), selenium (Smith et al., 1984; Cebra et al., 2003), and copper (Scaletti and Harmon, 2012) may improve PMN function and reduce disease incidence, particularly when diets are marginal in these substances.

To directly improve PMN function, one group of researchers subcutaneously injected recombinant bovine granulocyte colony-stimulating factor (rbG-CSF) daily and examined PMN number and function in cows with and without Staphylococcus aureus infection of 1 mammary quarter (Kehrli et al., 1991). They demonstrated a large increase in PMN number by rbG-CSF injection, as well as improved ingestion of bacteria and 
improved cytotoxicity by PMN. However, not every PMN function improved. For example, the ability of PMN to move randomly or toward a chemotactic target through agarose was reduced by rbG-CSF treatment.

The granulocyte colony-stimulating factor injection has been used in human medicine to increase PMN numbers in cancer patients who undergo myelosuppressive chemotherapy to improve their ability to fight infections (Hata et al., 2011; Inaba et al., 2011). A recent report compared daily dosing of rhG-CSF (average $4.8 \mathrm{~d}$ of treatment) with a single dose of a polyethylene glycolated form (covalently bound) of rhG-CSF (PEG rhG-CSF) and demonstrated better efficacy of PEG rhG-CSF in increasing PMN numbers in patients undergoing chemotherapy (Almenar Cubells et al., 2013). Administering human granulocyte colony-stimulating factor to patients with human immunodeficiency virus reduces the incidence of bacterial infections and the number of days spent in a hospital (Kuritzkes, 2000). The rhG-CSF was approved in the United States in 1991 for use in decreasing the incidence of infection, as manifested by febrile neutropenia in patients undergoing myelosuppressive chemotherapy (Crawford, 2003; Hartung et al., 2003), especially when a risk for infection was anticipated (before surgery, before chemotherapy).

We hypothesized that subcutaneous injection of PEG rbG-CSF at approximately $7 \mathrm{~d}$ before parturition and on the day of calving would increase PMN numbers and reverse the periparturient suppression of PMN function in dairy cows. The objective was to evaluate PMN number and function from $2 \mathrm{wk}$ before expected parturition to 2 wk after calving in periparturient Holstein cows treated or not treated with PEG rbG-CSF.

\section{MATERIALS AND METHODS}

\section{Animal Treatment and Sampling}

Twenty-one Holstein cows in their second pregnancy were selected and housed at the Iowa State University Dairy Farm. Cows were selected from the herd only if their BCS was at least 3.0 and not more than 3.75 and they showed no signs of lameness. Previous milk production was not factored into this decision to enroll the cows. Once enrolled in the study, the cows were alternately assigned into 2 groups based on expected calving date: control (CONT) cows received saline $(\mathrm{n}=10)$ and granulocyte colony-stimulating factor (GCSF) cows received PEG rbG-CSF $(\mathrm{n}=11)$. Treatments were administered via subcutaneous injection using an 18 gauge $\times 2.5$-cm needle. All cows were fed and managed following standard procedures of the Iowa State University Dairy Farm. A high-straw, low-DCAD close-up diet was fed the last 3 wk of gestation, followed by a corn silage-based lactation diet balanced for $35 \mathrm{~kg}$ of milk production. Blood samples were obtained Monday, Wednesday, and Friday from May 16 to August 17, 2012. Blood was collected from cattle by jugular venipuncture. Blood intended for PMN function assays was collected using acid citrate dextrose as an anticoagulant (Roth and Kaeberle, 1981b). Blood was also collected into separate tubes with EDTA.2K (for complete blood count) and heparin $\mathrm{Na}$ (for plasma isolation) as anticoagulants. Animals were handled using procedures approved by the Animal Care and Use Committee of Iowa State University.

The PEG rbG-CSF [approximately $15 \mathrm{mg}$ (as an active ingredient) $/ 3 \mathrm{~mL}$ per cow] or saline $(3 \mathrm{~mL} / \mathrm{cow})$ treatments were administered subcutaneously in the lumbar region twice. The first dose was administered approximately $7 \mathrm{~d}$ before expected parturition, depending on expected calving date and judgment of investigators based on physical changes including swelling of vulva and filling of udder. The second dose was administered within $24 \mathrm{~h}$ after calving. Neutrophil function, plasma BHBA, NEFA, and Ca, and complete blood count were evaluated 3 times a week (Monday, Wednesday, and Friday) beginning 2 to 3 wk before expected parturition and continuing until $2 \mathrm{wk}$ (13 to $16 \mathrm{~d}$ ) after parturition.

\section{Reagents}

The PEG rbG-CSF and sterile saline were provided by Elanco Animal Health in individual, prefilled 3-mL syringes with rubber cap for single use. They were kept in a refrigerator at $4^{\circ} \mathrm{C}$ until use.

All reagents for immunologic assays were obtained from Sigma Chemical Co. (St. Louis, MO) unless otherwise specified. A solution of 3,3',5,5'-tetramethylbenzidine hydrochloride ( $2.5 \mathrm{~m} M$ in water) was made fresh each day immediately before use. A solution of $\mathrm{H}_{2} \mathrm{O}_{2}$ (5.3 $\mathrm{m} M$ in water) was prepared fresh daily. The detergent cetyltrimethylammonium bromide $(0.02 \%$ in water) was used as the lysing agent for determining total myeloperoxidase (MPO) content of PMN. Cytochalasin B $(1 \mathrm{mg} / \mathrm{mL})$, phorbol 12-myristate 13-acetate (PMA; $1 \mathrm{mg} / \mathrm{mL}$ ), and calcium ionophore A23187 (1 $\mathrm{mg} / \mathrm{mL}$ ) were dissolved in dimethyl sulfoxide as stock solutions and stored at $-80^{\circ} \mathrm{C}$. Cytochrome $\mathrm{C}$ from equine heart was dissolved in Hanks' balanced salt solution (HBSS; Mediatech, Herndon, VA) at $37.5 \mathrm{mg} / \mathrm{mL}$ and stored at $-20 \mathrm{C}$ as a stock solution.

\section{Total and Differential White Blood Cell Count}

Enumerations of total PMN, monocytes, eosinophils, basophils, total white blood cells, and platelets in the 
whole blood were conducted using an Advia 120 Hematology Analyzer (Siemens Healthcare Diagnostics Inc., Deerfield, IL) at the Clinical Pathology Laboratory of the Iowa State University College of Veterinary Medicine. To determine the presence of band PMN, blood smear slides were prepared and stained. Smears were examined under the microscope and 100 leukocytes were counted to determine the percentage of band cells. Persons conducting the counts were blinded to the treatments.

\section{Plasma BHBA, NEFA, and Ca}

Both BHBA and Ca concentrations in plasma were determined by colorimetric assays using commercial kits adapted to microtiter plates [BHBA kit (H7587), Calcium arsenazo III kit (C7529), Pointe Scientific, Canton, MI]. The NEFA determinations were made by colorimetric assay adapted to microtiter plate using a commercial kit (Wako Chemicals USA, Richmond, VA).

\section{Neutrophil Isolation}

Isolation of PMN, and preparation of PMN suspensions for use in the assays were performed as described previously (Roth and Kaeberle, 1981b). Blood collected in acid citrate dextrose anticoagulant was transferred into a $50-\mathrm{mL}$ tube and centrifuged at $1,000 \times g$ for $20 \mathrm{~min}$ at room temperature. After centrifugation, the plasma, buffy coat layer and upper portion of packed red blood cells were removed, leaving PMN, which are denser than other cells and some red blood cells. The remaining red blood cells were lysed twice, and PMN were pelleted at $300 \times g$ for $5 \mathrm{~min}$. The PMN were resuspended and standardized to $5.0 \times 10^{7}$ cells $/ \mathrm{mL}$. All PMN function assays were conducted in 96-well flat bottom plates.

\section{MPO Exocytosis Assay}

Extracellularly released MPO following stimulation was expressed as a percentage of total MPO content inside unstimulated PMN (Palić et al., 2005). Total MPO content was determined by lysing PMN in 1 cell preparation with cetyltrimethylammonium bromide solution. Two more cell preparations were made from each sample: preparations stimulated with calcium ionophore A23187 $(5 \mu \mathrm{g} / \mathrm{mL})$ plus cytochalasin B $(5 \mu \mathrm{g} / \mathrm{mL})$ in HBSS, and those without stimulation (HBSS treated). For each preparation, $1.25 \times 10^{6} \mathrm{PMN}$ were added to a well in a microtiter plate. Total volume before adding $3,3^{\prime}, 5,5^{\prime}$-tetramethylbenzidine hydrochloride was 150 $\mu \mathrm{L} /$ well. All assays were performed in duplicate.
After incubation at $39^{\circ} \mathrm{C}$ for $20 \mathrm{~min}$, all wells received $50 \mu \mathrm{L} /$ well of $3,3^{\prime}, 5,5^{\prime}$-tetramethylbenzidine dihydrochloride $(3.25 \mathrm{mM})$, followed immediately by the addition of $50 \mu \mathrm{L} /$ well of $\mathrm{H}_{2} \mathrm{O}_{2}(5 \mathrm{~m} M)$. After 2 min of color development at room temperature, the reaction was stopped by the addition of $50 \mu \mathrm{L} /$ well of 2 $\mathrm{N} \mathrm{H}_{2} \mathrm{SO}_{4}$. Plates were centrifuged at $600 \times g$ for 2 min at room temperature, and $200 \mu \mathrm{L} /$ well of supernatant was transferred to a second plate. The optical density (OD) was determined at $405 \mathrm{~nm}$ using a microtiter plate spectrophotometer. The percentage of MPO released from PMN was determined for each calf using

$$
\begin{gathered}
\text { Exocytosis }(\%)=[\mathrm{OD} \text { of stimulated } \\
(\text { or HBSS-treated }) \mathrm{PMN}] /(\mathrm{OD} \text { of lysed PMN }) \times 100 \text {. }
\end{gathered}
$$

\section{Oxidative Burst Assay}

Cytochrome $\mathrm{C}$ reduction (Roth et al., 2001) was used to detect extracellular $\mathrm{O}_{2}{ }^{-}$. Neutrophils $\left(2.5 \times 10^{6}\right)$ were added to duplicate wells of a microtiter plate, which contained cytochrome $\mathrm{C}$ (final concentration $=487 \mu \mathrm{g}$ / $\mathrm{mL}$ ). One well was treated with HBSS and another was treated with HBSS plus PMA (final concentration $=0.5 \mu \mathrm{g} / \mathrm{mL}$ ). Final volume in each well was $300 \mu \mathrm{L}$. Each plate was incubated at $39 \mathrm{C}$ for $15 \mathrm{~min}$.

Immediately after incubation, OD (total amount of $\mathrm{O}_{2}{ }^{-}$released extracellularly, which reduces cytochrome $\mathrm{C}$ and generates color) was determined using a plate reader at 2 wavelengths $(\mathrm{OD}=\mathrm{V} 1-\mathrm{V} 2 ; \mathrm{V} 1=550 \mathrm{~nm}$ and $\mathrm{V} 2=650 \mathrm{~nm})$.

\section{Phagocytosis}

Phagocytosis of Staph. aureus was determined by flow cytometric detection of fluorescein isothiocyanate (FITC)-labeled bacteria in PMN. Bacteria were grown in brain heart infusion plus yeast extract broth with $0.5 \mathrm{mg} / \mathrm{mL}$ of FITC (White-Owen et al., 1992). At log phase growth, bacteria were washed with PBS twice and heat-killed at $60^{\circ} \mathrm{C}$ for $120 \mathrm{~min}$. Bacteria were washed with PBS again and resuspended in brain heart infusion plus yeast extract broth, the stock solution was then aliquoted into tubes. Aliquots were kept at $-20^{\circ} \mathrm{C}$ until use. On the day of assay, aliquots were diluted with HBSS that contained $20 \%$ bovine serum (pooled from 3 steers) to opsonize the bacteria. Opsonized bacteria $\left(1.25 \times 10^{5}\right)$ and PMN $\left(1.25 \times 10^{4}\right)$ were placed into a well together with $3 \%$ fetal bovine serum in HBSS. After incubation at $39^{\circ} \mathrm{C}$ for $20 \mathrm{~min}$, the plate was centrifuged at $430 \times g$ for 2 min at room temperature, and sedimented PMN were washed once with PBS and resuspended with 1\% formaldehyde (Polysciences, 
Warrington, PA) in PBS. Data were acquired by a BD Canton flow cytometer (BD Biosciences, San Jose, CA) and analyzed using FlowJo software (TreeStar, Ashland, OR). The percentage of phagocytosis-positive cells was determined by comparing with fluorescence of the same PMN without FITC labeled Staph. aureus. Mean fluorescent intensity was also determined for FITC-positive cells as an index of number of Staph. aureus ingested by each PMN.

\section{Milk Yield}

Milk production per cow was recorded using a computer-operated automatic recording device (except for the colostrum). Colostrum was collected and weighed by personnel at the Iowa State University Dairy Farm separately.

\section{Statistical Analysis}

Data were analyzed by repeated measures of GLIMMIX procedure (SAS Institute Inc., Cary, NC). The model included the fixed effects of treatment (GCSF vs. CONT), time (days relative to parturition), and treatment by time interaction. The model included a random effect of cows nested within treatment, with a compound symmetry covariance structure.

For statistical analysis purposes, data were assigned to time periods based on the days relative to parturition during which blood samples had been obtained. When more than 1 blood sample was obtained in a sampling period, the average value of a parameter for that animal during that time period was used. For samples taken before injection, data from -14 to $-8 \mathrm{~d}$ were pooled and compared between groups.

Data are expressed as mean \pm SEM. The difference between groups at each time point was determined by Student's $t$-test based on least squares means; $P \leq 0.05$ was considered significant. White blood cell counts were converted to $\log 10$ for statistical analysis. The data were used to generate graphs from -5 to $13 \mathrm{~d}$ postpartum. Prepartum data of GCSF cows were used only if they had been treated by injection of GCSF before that time point.

\section{RESULTS}

\section{Samples}

Eleven cows received the first dose of PEG rbG-CSF at $6.18+1.01 \mathrm{~d}$ before calving (range 11-1 d before calving). The second dose was administered within $24 \mathrm{~h}$ of calving. Due to the different injection times relative to parturition, the number of cows sampled at -14 (4, $6),-11(8,8),-8(10,8),-5(10,5),-2(10,10), 1$ $(10,11), 4(10,11), 7(10,11), 10(9,11)$, and $13(9,11)$ $\mathrm{d}$ after calving for CONT and GCSF cows, respectively, are designated within parenthesis. No differences were noted between treatment groups before injection in any parameters (Table 1 ). The results of statistical analysis after treatments were summarized in Table 2.

\section{Disease Incidence and Treatment}

Seven cows ( 3 in CONT and 4 in GCSF) had clinically apparent problems. Cows with metritis were diagnosed based on a fetid vaginal discharge. Metritis was not treated, simply recorded. We included all of these cows in our data analysis. However, 1 cow was administered dexamethasone for a prolonged ketosis $9 \mathrm{~d}$ after calving. The data of this cow after dexamethasone injection were eliminated from the statistical analysis. Dexamethasone is a corticosteroid that has been shown previously to induce a transient neutrophilia and impair PMN function (Roth and Kaeberle, 1981a; Burton and Kehrli, 1995; Burton et al., 1995). Therefore, exclusion of this animal's data after administration of dexamethasone eliminates the confounding effect of an exogenous corticosteroid.

Table 1. Data taken from before recombinant bovine granulocyte colony-stimulating factor covalently bound to polyethylene glycol (GCSF) injections and corresponding data taken from control (CONT) cows

\begin{tabular}{lccc}
\hline & \multicolumn{2}{c}{ Group (sampling date: $-14,-10,-8 \mathrm{~d})$} & \\
\cline { 2 - 3 } Item & $\mathrm{CONT}(\mathrm{n}=4,8,10)$ & $\mathrm{GCSF}(\mathrm{n}=6,8,8)$ & $P$-value \\
\hline Polymorphonuclear neutrophil $\left(\mathrm{PMN} ; \mathrm{N}^{6} / \mathrm{mL}\right)$ & $4.02 \pm 0.28$ & $3.90 \pm 0.31$ & 0.618 \\
Band PMN $\left(10^{6} / \mathrm{mL}\right)$ & $0.00 \pm 0.01$ & $0.00 \pm 0.00$ & 0.634 \\
Myeloperoxidase (MPO) released from stimulated & $44.2 \pm 3.1$ & $48.8 \pm 3.8$ & 0.137 \\
PMN (\%) & $2.05 \pm 0.05$ & $2.00 \pm 0.06$ & 0.304 \\
Total MPO (optical density; OD) & $0.91 \pm 0.07$ & $0.99 \pm 0.09$ & 0.272 \\
MPO released from stimulated PMN (OD) & $0.51 \pm 0.01$ & $0.51 \pm 0.02$ & 0.681 \\
Oxidative burst (OD) & $50.3 \pm 4.7$ & $52.6 \pm 4.0$ & 0.543 \\
Phagocytosis (\%) & $0.49 \pm 0.09$ & $0.41 \pm 0.11$ & 0.371 \\
Plasma NEFA (mEq) & $9.63 \pm 0.25$ & $9.87 \pm 0.16$ & 0.209 \\
Plasma Ca (mg/dL) & & & \\
\hline
\end{tabular}


Table 2. Results of statistical analysis for data obtained after injection

\begin{tabular}{lccc}
\hline Item & & & $\begin{array}{c}\text { Treatment } \\
\text { by time }\end{array}$ \\
\hline Polymorphonuclear neutrophil $\left(\mathrm{PMN} ; 10^{6} / \mathrm{mL}\right)$ & $<0.0001$ & 0.164 & 0.291 \\
Band PMN $\left(10^{6} / \mathrm{mL}\right)$ & $<0.0001$ & 0.003 & $<0.0001$ \\
Myeloperoxidase (MPO) released from stimulated & $<0.0001$ & $<0.0001$ & 0.046 \\
PMN (\%) & & & \\
Total MPO (optical density; OD) & 0.007 & 0.096 & 0.680 \\
MPO released from stimulated PMN (OD) & 0.054 & 0.001 & 0.850 \\
Oxidative burst (OD) & 0.736 & 0.169 & 0.544 \\
Phagocytosis (\%) & 0.268 & 0.954 & 0.124 \\
Plasma NEFA (mEq) & 0.161 & $<0.0001$ & 0.315 \\
Plasma BHBA (mM) & 0.585 & 0.100 & 0.718 \\
Plasma Ca (mg/dL) & 0.439 & $<0.0001$ & 0.008 \\
Milk (kg/d) & 0.545 & $<0.0001$ & 0.072 \\
\hline
\end{tabular}

\section{White Blood Cell Counts}

The PEG rbG-CSF injection significantly increased total PMN and band PMN numbers (Figure $1 \mathrm{~A}$ and B). The difference in total PMN number was significant at all sampling points from -5 to $13 \mathrm{~d}$ after calving. Total number of PMN had a significant treatment effect $(P<$ $0.0001)$, with no effect of time around parturition and no treatment by time effects (Table 2). In GCSF cows, PMN counts peaked on $\mathrm{d} 1$ at $18.99 \pm 2.18$ million cells/ $\mathrm{mL}$, followed by a gradual decrease. In CONT cows, the number remained similar to baseline for $-5,-2$, and $1 \mathrm{~d}(4.38 \pm 1.13,4.36 \pm 0.9$, and $4.32 \pm 2.29$ million cells/mL, respectively). The PMN counts declined from calving until the end of sampling (CONT 13 d: $3.79 \pm$ 1.14 million cells $/ \mathrm{mL}$ ). The increase in PMN in GCSF cows consisted mostly of mature PMN. Only a fraction of increased PMN was due to an increase in the number of the band form of PMN, which are younger PMN recently released from the bone marrow. The number of band PMN exhibited treatment, time, and treatment by time effects $(P<0.0001,=0.003$, and $<0.0001$, respectively). Significant differences $(P<0.005)$ across treatments in band PMN number were observed from -5 to $7 \mathrm{~d}$ after calving. The slightly elevated band PMN number in CONT cows on $10 \mathrm{~d}$ was due to a single cow, which had metritis; she was not given any treatment for the metritis. Total white blood cell count increased with GCSF treatment, which was almost entirely attributable to increased PMN numbers, as other cell types counted in the complete cell count were unaffected (data not shown).

\section{MPO Exocytosis}

The percentage of MPO released upon stimulation of PMN exhibited significant treatment $(P<0.0001)$, time $(P<0.0001)$, and treatment by time effects $(P<$

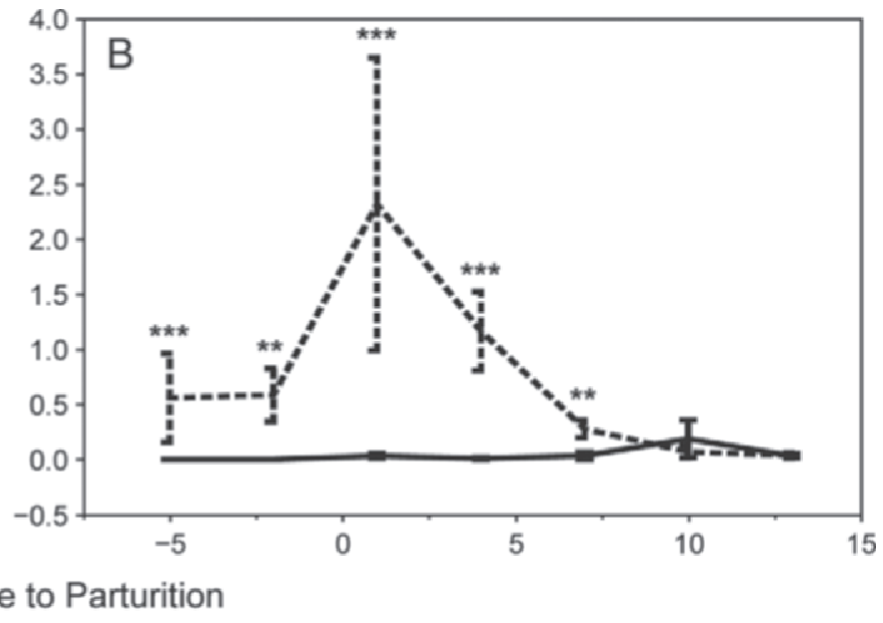

Figure 1. The effect of recombinant bovine granulocyte colony stimulating factor covalently bound to polyethylene glycol (PEG rbG-CSF) on (A) total polymorphonuclear neutrophil (PMN) number and (B) band form neutrophil number. A solid line represents control (CONT) cows, and dashed line represents PEG rbG-CSF-injected (GCSF) cows. An asterisk $(*)$ represents $P<0.05$; two asterisks $(* *)$ represents $P<0.01$; three asterisks $(* * *)$ represents $P<0.005$ in comparison between groups at the same sampling point. 

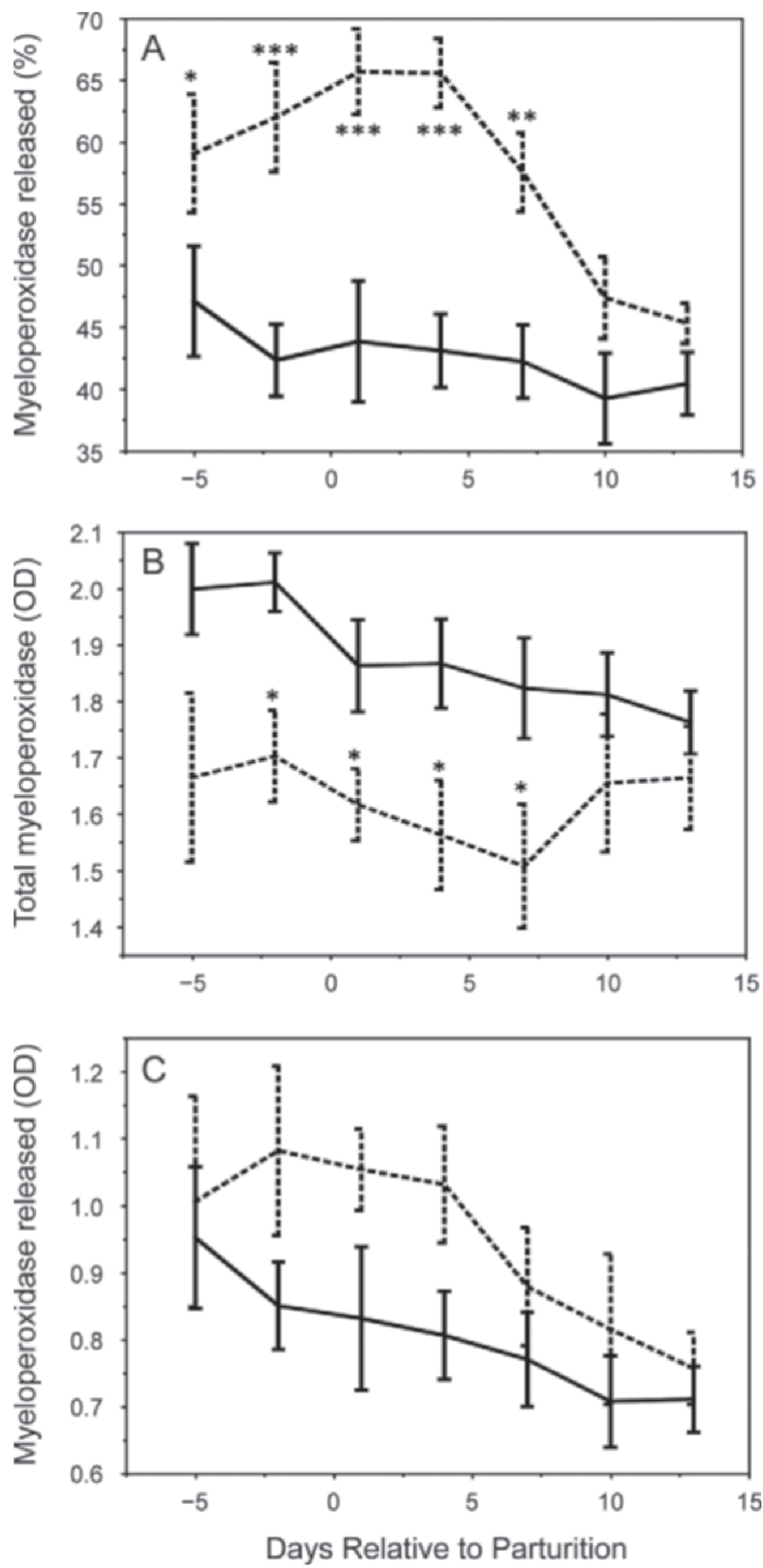

Figure 2. The effect of recombinant bovine granulocyte colony stimulating factor covalently bound to polyethylene glycol (PEG rbGCSF) on (A) the percentage of myeloperoxidase released from stimulated neutrophils, (B) total myeloperoxidase inside neutrophils without stimulation expressed as optical density (OD), and (C) myeloperoxidase released from stimulated neutrophils expressed as OD. A solid line represents control (CONT) cows, and dashed line represents PEG rbG-CSF-injected (GCSF) cows. An asterisk $\left(^{*}\right)$ represents $P<0.05$; two asterisks $(* *)$ represents $P<0.01$; three asterisks (***) represents $P<0.005$ in comparison between groups at the same sampling point.
0.05; Figure 2A and Table 2). The PMN of GCSF cows exhibited a significantly higher percentage of MPO release compared with CONT from -5 to $7 \mathrm{~d}$ after calving, with peak MPO exocytosis at $1(66 \pm 4 \%)$ and $4(65.6 \pm 2.8 \%)$ d after calving. In CONT cows, MPO exocytosis tended to decline from $-5(47 \pm 4 \%)$ to 10 $(39 \pm 4 \%)$ d, with a slight recovery on 13 d. On d 13, MPO exocytosis of CONT cows was similar to that of the GCSF cows (CONT vs. GCSF, $40.4 \pm 2.2$ vs. 45.3 $\pm 2.5 \%$ ).

Total MPO, expressed as OD, determined for lysed PMN showed a significant treatment effect $(P=0.007)$ without time and treatment by time effects (Figure 2B and Table 2). PMN of GCSF cows had significantly lower total MPO from -3 to $7 \mathrm{~d}$ compared with CONT cows. Total MPO declined in both groups during the sampling period. In CONT cows, the declining trend lasted through the end of the sampling period. In GCSF cows, total PMN MPO reached a nadir at $7 \mathrm{~d}$ after calving, followed by a small increase; it was not different from CONT cows at 10 and $13 \mathrm{~d}$.

In spite of lower total MPO in GCSF-treated cows, the released MPO from stimulated PMN, expressed as OD (Figure 2C), were slightly higher than CONT at -2 $(P=0.06), 1(P=0.07)$, and $4(P=0.07) \mathrm{d}$ after calving. A significant treatment effect $(P=0.05)$ on MPO release by stimulated PMN was observed, expressed as OD. The MPO exocytosis by resting, nonstimulated (HBSS-treated) PMN showed large day-to-day variation in both groups without any difference between groups (Table 2).

\section{Oxidative Burst}

Production of superoxide anion remained relatively constant for CONT cows throughout the duration of the study. No significant effect of GCSF treatment on production of superoxide anion was seen in either PMA-stimulated (Figure 3A) or resting PMN (data not shown).

\section{Phagocytosis}

Both CONT and GCSF groups exhibited large dayto-day variation in phagocytosis activity without any treatment, time, or treatment by time effects in either percentage of phagocytizing PMN (Figure 3B) or mean fluorescent intensity (data not shown).

\section{Plasma Ca, NEFA, and BHBA}

These determinations were conducted as means of screening for adverse effects of GCSF treatment on other health parameters of periparturient cows. Al- 

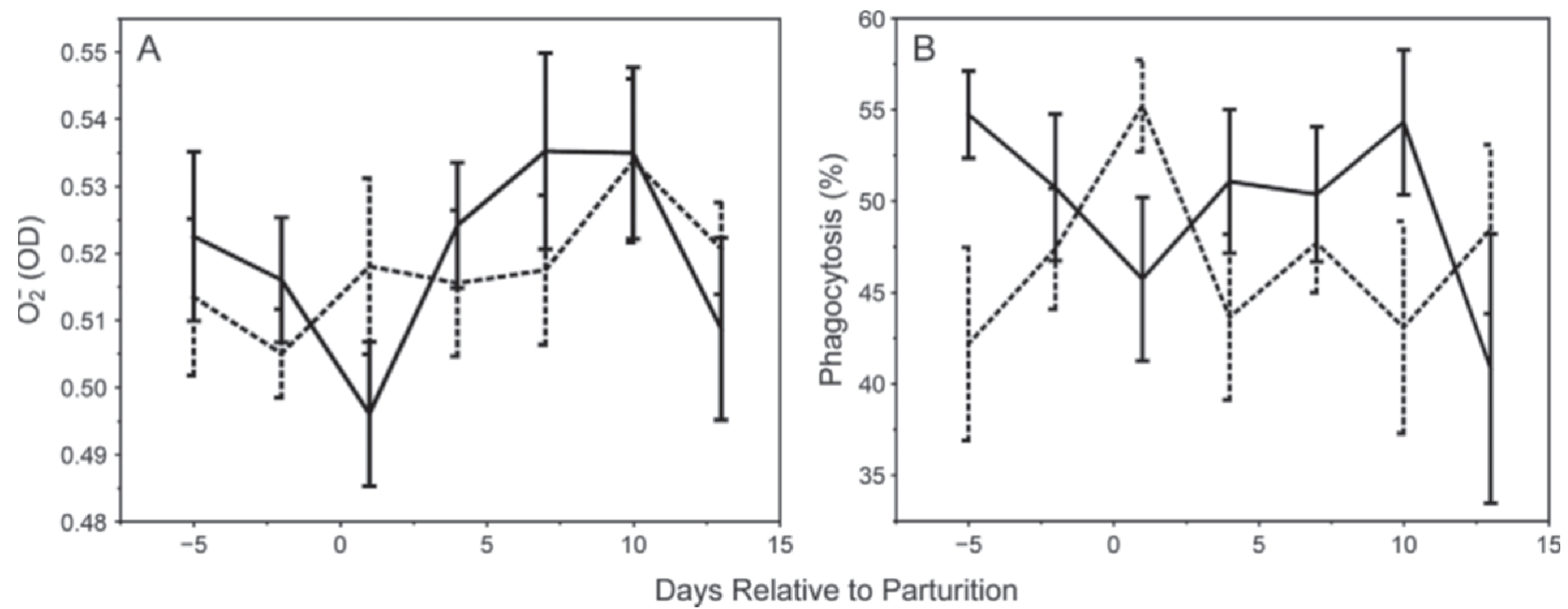

Figure 3. The effect of recombinant bovine granulocyte colony stimulating factor covalently bound to polyethylene glycol (PEG rbG-CSF) on (A) superoxide anion $\left(\mathrm{O}_{2}^{-}\right)$release (optical density; OD) from activated neutrophils and (B) phagocytosis of opsonized Staphylococcus aureus, expressed as percentage of positive neutrophils. A solid line represents control (CONT) cows, and dashed line represents PEG rbG-CSF-injected (GCSF) cows. No significant differences were observed between groups at any sampling point.

though no cows suffered from milk fever or severe hypocalcemia, both groups exhibited a decline in plasma Ca from -2 to $4 \mathrm{~d}$ after calving compared with -5 d $(P<0.05 ;$ Figure $4 \mathrm{~A})$. However, CONT cows had significantly lower plasma Ca than GCSF cows at -2 d $(P=0.02)$. Administration of granulocyte colonystimulating factor had no detectable negative effects on Ca homeostasis.

Nonesterified fatty acids increased after calving in both groups, reaching a peak at 4 (GCSF) and $7 \mathrm{~d}$ (CONT), followed by a decline (Figure 4B; time effect, $P<0.0001)$. The pattern of change was similar in both groups, but GCSF cows had significantly lower NEFA at $10 \mathrm{~d}(P=0.03)$ compared with CONT. The BHBA was similar in both groups after calving without any time, treatment, or treatment by time effects (Figure $4 \mathrm{C})$. Administration of granulocyte colony-stimulating factor had no detectable negative effects on serum NEFA or BHBA, suggesting it did not negatively affect feed intake.

\section{Milk Yield}

Milk yield during the first $14 \mathrm{~d}$ of lactation was similar for both groups (Figure 4D), suggesting no major negative effect of granulocyte colony-stimulating factor treatment on milk production.

\section{DISCUSSION}

Granulocyte colony-stimulating factor is a glycoprotein cytokine that stimulates the bone marrow to produce stem cells and granulocytes and release granulocytes into the bloodstream. A recombinant form of human granulocyte colony-stimulating factor is used for certain cancer patients to accelerate recovery from neutropenia after chemotherapy (Lyman et al., 2013). Chemotherapy can cause myelosuppression and unacceptably low levels of white blood cells, making patients susceptible to infections and sepsis (Ching, 2013).

Granulocyte colony-stimulating factor stimulates myeloid progenitor cell proliferation and increases the number of PMN in the bone marrow storage pool, as well as the number of circulating mature PMN in humans (Basu et al., 2002; Gregory et al., 2007). We examined both mature and immature PMN (band cell) numbers in the peripheral circulation. A PEG rbG-CSF injection markedly increased both mature and immature PMN, but the majority of the increased PMN induced by PEG rbG-CSF were mature cells, similar to the report for periparturient cows injected daily with rbG-CSF (Kehrli et al., 1991). The number of mature cells remained high even at $13 \mathrm{~d}$ after the completion of the injection. This demonstrates a more persistent effect of PEG rbG-CSF when compared with daily injection of rbG-CSF. In CONT cows, peripheral blood PMN numbers decreased after calving. Neutropenia has often been observed in periparturient cows (Kehrli and Goff, 1989; Kehrli et al., 1989; Kimura et al., 1999). Bacteria can be cultured from the uterus of nearly all cows in the first day after parturition (Sheldon et al., 2006). It is suspected that neutropenia may result from recruitment of PMN to the uterus to fight bacteria that have invaded the uterus. Neutropenia may leave the 

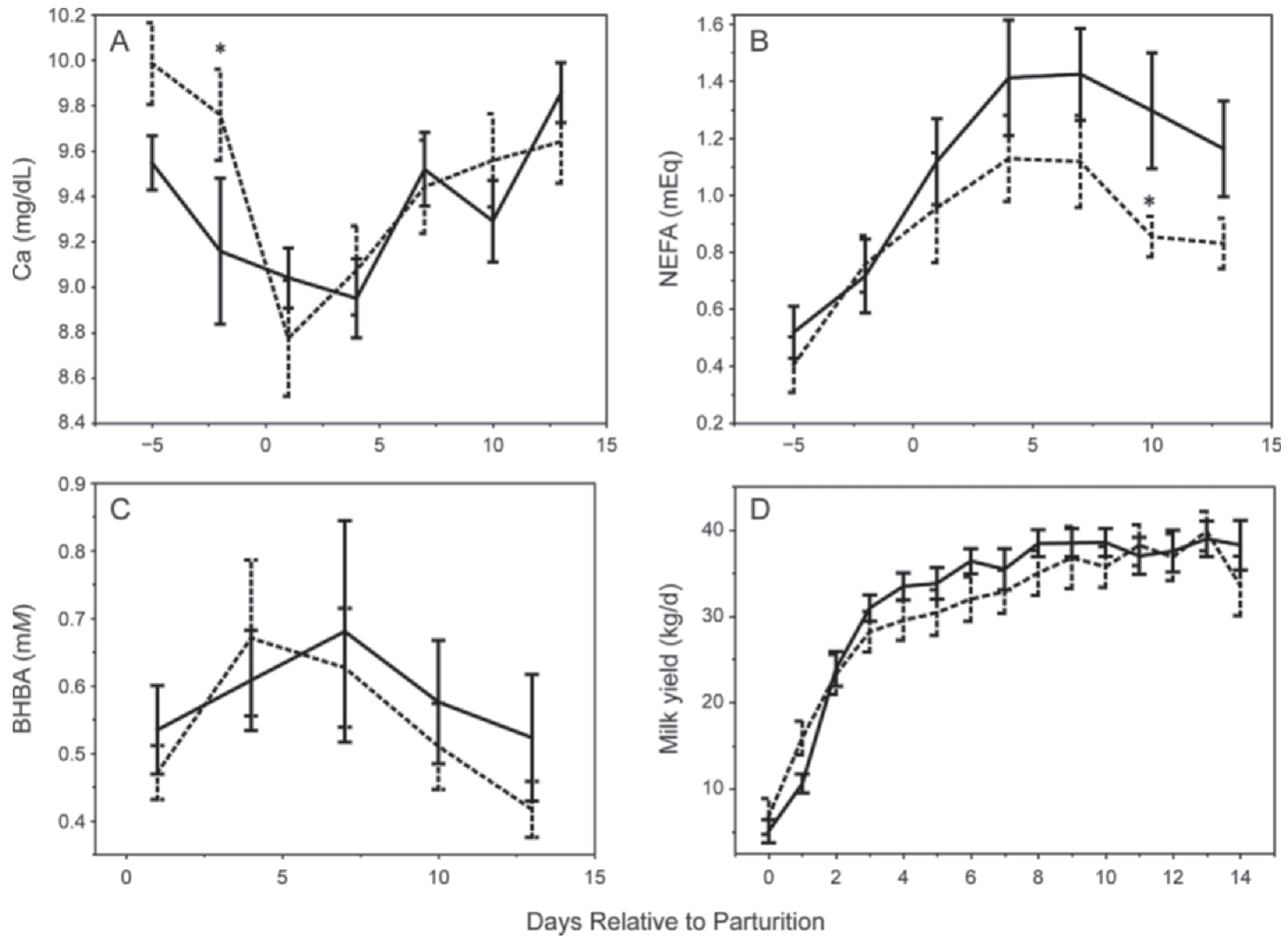

Figure 4. The effect of granulocyte colony-stimulating factor on (A) plasma Ca $(\mathrm{mg} / \mathrm{dL})$, (B) plasma NEFA (mEq), (C) BHBA (mM), and (D) milk yield $(\mathrm{kg} / \mathrm{d})$. A solid line represents control cows and a dashed line represents recombinant bovine granulocyte colony-stimulating factor covalently bound to polyethylene glycol-injected cows. An asterisk $\left(^{*}\right)$ indicates $P<0.05$ comparing between cows at the same sampling point.

cow susceptible to other infections, such as mastitis. Increasing the available pool of PMN in circulation using PEG rbG-CSF during the periparturient period could increase resistance to infectious diseases, as it does in immune-compromised humans (Hartung et al., 2003), especially when administered in anticipation of a period of increased risk of infection.

Seven cows exhibited health problems based on clinical signs or reduced milk production. Although we would ultimately believe fewer health problems would be observed in PEG rbG-CSF-injected cows, the current study had insufficient power to prove clinical health benefits in response to PEG rbG-CSF treatment.

The MPO is one of the enzymes present in primary granules of PMN. Upon activation, MPO is released into phagosomes as well as outside the PMN (exocytosis; Mitchell et al., 2008). The MPO generates the most powerful microbiocidal substances available to PMN, thus MPO release is important to PMN bactericidal capacity (Klebanoff et al., 2013). In the present study, MPO exocytosis decreased in periparturient cows. This decrease in neutrophil MPO exocytosis function is similar to earlier studies utilizing PMN iodination assay, which also approximated MPO exocytosis (Kehrli et al., 1991; Kimura et al., 1999, 2002). Although total MPO in PMN was lower in GCSF cows, the percentage of release and the quantity of MPO released from PMN were higher than what was observed with CONT cows. Healthy human subjects injected with rhG-CSF had increased plasma levels of MPO (Morabito et al., 2005); therefore, the lower total MPO in PMN from GCSF cows may be caused by moderate in vivo exocytosis of MPO from PEG rbG-CSF-primed PMN. The remaining intracellular MPO was apparently released more 
efficiently from the already primed PMN of the GCSF cows when they were stimulated with calcium ionophore. As impaired PMN iodination has been reported to be associated with postpartum disease occurrence (Cai et al., 1994; Detilleux et al., 1995), increased MPO release by PEG rbG-CSF administration is promising as an intervention for periparturient impairment in PMN function, and should lead to improved disease prevention.

No significant differences were noted between treatment groups in release of superoxide anion (oxidative burst) or phagocytosis by PMN during the experimental period. Reports of changes in both oxidative burst and phagocytosis during the periparturient period have varied. Meglia et al. (2005) reported no change in oxidative burst, whereas others (Kehrli et al., 1989; Piccinini et al., 2004) reported a decrease in oxidative burst in the periparturient period. Kehrli et al. (1989) reported higher phagocytosis around the time of calving, whereas other researchers reported a decrease (Tan et al., 2012) or no change (Sander et al., 2011; Graugnard et al., 2012) in phagocytic activity in the periparturient dairy cow. These differences may have been due to differences in experimental design or assays used.

We observed no significant effect of PEG rbG-CSF treatment on phagocytosis of Staph. aureus by PMN. Kehrli et al. (1991) previously reported an increase in phagocytosis with rbG-CSF treatment. This difference may be due to differences in assay methodology or differences in the rbG-CSF used.

All PMN function assays were conducted using a standardized number of PMN. Administration of PEG rbG-CSF caused an increase in percent exocytosis of MPO, but a decrease in total MPO. The MPOcatalyzed reaction between halide ions and hydrogen peroxide is a major killing mechanism of neutrophils. The greatest single effect of PEG rbG-CSF administration was a dramatic increase in circulating numbers of neutrophils. The increased numbers of neutrophils ready to move to a site early in the course of an infection, along with the increased ability to release MPO, could improve the ability of the cow to prevent clinical disease in the periparturient period.

For possible side effects of PEG rbG-CSF administration, we selected plasma Ca, NEFA, BHBA, and milk yield as screening parameters, as these parameters are commonly affected by feed intake or health condition of periparturient dairy cows. No consistent significant effects of PEG rbG-CSF treatment were observed on these parameters. These data, based on a small number of animals, suggest that no negative effects exist on these parameters by PEG rbG-CSF treatment.

Treatment with PEG rbG-CSF greatly increased PMN numbers in the circulation of treated cows.
Overall, our data suggest PMN function in PEG rbGCSF-treated cows was similar to that of CONT cow PMN on an individual PMN basis, with the exception of improved MPO exocytosis. The dramatic increase in PMN number should enable more PMN to travel to an early site of infection, such as the uterus or mammary gland, without experiencing neutropenia. Further evaluation of PEG rbG-CSF for prevention of periparturient diseases in dairy cattle is warranted.

\section{ACKNOWLEDGMENTS}

We are grateful for professional technical assistance by Thomas Skadow (Iowa State University, Ames) for bleeding and PMN assays. Our appreciation also goes to Benjamin Schmidt and Andrew Allison (students at Iowa State University) for their help of bleeding and observation of cows. This research was funded by ELANCO Animal Health, Greenfield, Indiana.

\section{REFERENCES}

Almenar Cubells, D., C. Bosch Roig, E. Jimenez Orozco, R. Alvarez, J. M. Cuervo, N. Diaz Fernandez, A. B. Sanchez Heras, A. Galan Brotons, V. Giner Marco, and M. D. V. M. Codes. 2013. Effectiveness of daily versus non-daily granulocyte colony-stimulating factors in patients with solid tumours undergoing chemotherapy: A multivariate analysis of data from current practice. Eur. J. Cancer Care (Engl.) 22:400-412.

Basu, S., A. Dunn, and A. Ward. 2002. G-CSF: Function and modes of action. Int. J. Mol. Med. 10:3-10.

Burton, J. L., and M. E. Kehrli Jr.. 1995. Regulation of neutrophil adhesion molecules and shedding of Staphylococcus aureus in milk of cortisol-and dexamethasone-treated cows. Am. J. Vet. Res. 56:997-1006.

Burton, J. L., M. E. Kehrli Jr., S. Kapil, and R. L. Horst. 1995. Regulation of L-selectin and CD18 on bovine neutrophils by glucocorticoids: Effects of cortisol and dexamethasone. J. Leukoc. Biol. 57:317-325.

Burton, J. L., S. A. Madsen, J. Yao, S. S. Sipkovsky, and P. M. Coussens. 2001. An immunogenomics approach to understanding periparturient immunosuppression and mastitis susceptibility in dairy cows. Acta Vet. Scand. 42:407-424.

Cai, T.-Q., P. G. Weston, L. A. Lund, B. Brodie, D. J. McKenna, and W. C. Wagner. 1994. Association between neutrophil functions and periparturient disorders in cows. Am. J. Vet. Res. 55:934-943.

Cebra, C. K., J. R. Heidel, R. O. Crisman, and B. V. Stang. 2003. The relationship between endogenous cortisol, blood micronutrients, and neutrophil function in postparturient Holstein cows. J. Vet. Intern. Med. 17:902-907.

Ching, L. C. 2013. Cochrane review summary for cancer nursing: Lowbacterial diet versus control diet to prevent infection in cancer patients treated with chemotherapy causing episodes of neutropenia. Cancer Nurs. 36:493.

Crawford, J. 2003. Safety and efficacy of pegfilgrastim in patients receiving myelosuppressive chemotherapy. Pharmacotherapy $23: 15 \mathrm{~S}-19 \mathrm{~S}$

Detilleux, J. C., M. E. Kehrli Jr., J. R. Stabel, and A. E. Freeman. 1995. Study of immunological dysfunction in periparturient Holstein cattle selected for high and average milk production. Vet. Immunol. Immunopathol. 44:251-267.

Goff, J. P., K. Kimura, and R. L. Horst. 2002. Effect of mastectomy on milk fever, energy, and vitamins A, E, and beta-carotene status at parturition. J. Dairy Sci. 85:1427-1436. 
Graugnard, D. E., M. Bionaz, E. Trevisi, K. M. Moyes, J. L. SalakJohnson, R. L. Wallace, J. K. Drackley, G. Bertoni, and J. J. Loor. 2012. Blood immunometabolic indices and polymorphonuclear neutrophil function in peripartum dairy cows are altered by level of dietary energy prepartum. J. Dairy Sci. 95:1749-1758.

Gregory, A. D., L. A. Hogue, T. W. Ferkol, and D. C. Link. 2007. Regulation of systemic and local neutrophil responses by G-CSF during pulmonary Pseudomonas aeruginosa infection. Blood 109:3235-3243.

Hammon, D. S., I. M. Evjen, T. R. Dhiman, J. P. Goff, and J. L. Walters. 2006. Neutrophil function and energy status in Holstein cows with uterine health disorders. Vet. Immunol. Immunopathol. $113: 21-29$

Hartung, G., M. Zeis, B. Glass, P. Dreger, J. Steinmann, N. Schmitz, and L. Uharek. 2003. Enhanced antileukemic activity of allogeneic peripheral blood progenitor cell transplants following donor treatment with the combination of granulocyte colony-stimulating factor (G-CSF) and stem cell factor (SCF) in a murine transplantation model. Bone Marrow Transplant. 32:49-56.

Hata, A., N. Katakami, S. Fujita, R. Kaji, S. Nanjo, K. Otsuka, Y. Kida, Y. Higashi, R. Tachikawa, M. Hayashi, T. Nishimura, and K. Tomii. 2011. Amrubicin at a lower-dose with routine prophylactic use of granulocyte-colony stimulating factor for relapsed small-cell lung cancer. Lung Cancer 72:224-228.

Inaba, H., X. Cao, S. Pounds, C. H. Pui, J. E. Rubnitz, R. C. Ribeiro, and B. I. Razzouk. 2011. Randomized trial of 2 dosages of prophylactic granulocyte-colony-stimulating factor after induction chemotherapy in pediatric acute myeloid leukemia. Cancer 117:1313-1320.

Kehrli, M. E., Jr., and J. P. Goff. 1989. Periparturient hypocalcemia in cows: Effects on peripheral blood neutrophil and lymphocyte function. J. Dairy Sci. 72:1188-1196.

Kehrli, M. E., Jr., J. P. Goff, M. G. Stevens, and T. C. Boone. 1991. Effects of granulocyte colony-stimulating factor administration to periparturient cows on neutrophils and bacterial shedding. J. Dairy Sci. 74:2448-2458.

Kehrli, M. E., Jr., B. J. Nonnecke, and J. A. Roth. 1989. Alterations in bovine neutrophil function during the periparturient period. Am. J. Vet. Res. 50:207-214.

Kimura, K., J. P. Goff, and M. E. Kehrli Jr. 1999. Effects of the presence of the mammary gland on expression of neutrophil adhesion molecules and myeloperoxidase activity in periparturient dairy cows. J. Dairy Sci. 82:2385-2392.

Kimura, K., J. P. Goff, M. E. Kehrli Jr., and T. A. Reinhardt. 2002. Decreased neutrophil function as a cause of retained placenta in dairy cattle. J. Dairy Sci. 85:544-550.

Kimura, K., T. A. Reinhardt, and J. P. Goff. 2006. Parturition and hypocalcemia blunts calcium signals in immune cells of dairy cattle. J. Dairy Sci. 89:2588-2595.

Klebanoff, S. J., A. J. Kettle, H. Rosen, C. C. Winterbourn, and W. M. Nauseef. 2013. Myeloperoxidase: A front-line defender against phagocytosed microorganisms. J. Leukoc. Biol. 93:185-198.

Kuritzkes, D. R. 2000. Neutropenia, neutrophil dysfunction, and bacterial infection in patients with human immunodeficiency virus disease: The role of granulocyte colony-stimulating factor. Clin. Infect. Dis. 30:256-260.

Lyman, G. H., D. C. Dale, E. Culakova, M. S. Poniewierski, D. A. Wolff, N. M. Kuderer, M. Huang, and J. Crawford. 2013. The impact of the granulocyte colony-stimulating factor on chemotherapy dose intensity and cancer survival: A systematic review and meta-analysis of randomized controlled trials. Ann. Oncol. $24: 2475-2484$.

Martinez, N., C. A. Risco, F. S. Lima, R. S. Bisinotto, L. F. Greco, E. S. Ribeiro, F. Maunsell, K. Galvao, and J. E. Santos. 2012. Evalu- ation of peripartal calcium status, energetic profile, and neutrophil function in dairy cows at low or high risk of developing uterine disease. J. Dairy Sci. 95:7158-7172.

Meglia, G. E., A. Johannisson, S. Agenas, K. Holtenius, and K. P. Waller. 2005. Effects of feeding intensity during the dry period on leukocyte and lymphocyte sub-populations, neutrophil function and health in periparturient dairy cows. Vet. J. 169:376-384.

Mitchell, T., A. Lo, M. R. Logan, P. Lacy, and G. Eitzen. 2008. Primary granule exocytosis in human neutrophils is regulated by Rac-dependent actin remodeling. Am. J. Physiol. Cell Physiol. 295:C1354-C1365.

Morabito, F., A. Tomaino, M. Cristani, M. Martino, P. L. Minciullo, A. Saija, and S. Gangemi. 2005. In vivo time course of plasma myeloperoxidase levels after granulocyte colony-stimulating factorinduced stem cell mobilization. Transfus. Med. 15:425-428.

Palić, D., C. B. Andreasen, B. W. Menzel, and J. A. Roth. 2005. A rapid, direct assay to measure degranulation of primary granules in neutrophils from kidney of fathead minnow (Pimephales promelas Rafinesque, 1820). Fish Shellfish Immunol. 19:217-227.

Piccinini, R., E. Binda, M. Belotti, G. Casirani, and A. Zecconi. 2004 The evaluation of non-specific immune status of heifers in field conditions during the periparturient period. Vet. Res. 35:539-550.

Politis, I., M. Hidiroglou, T. R. Batra, J. A. Gilmore, R. C. Gorewit, and H. Scherf. 1995. Effects of vitamin E on immune function of dairy cows. Am. J. Vet. Res. 56:179-184.

Politis, I., N. Hidiroglou, F. Cheli, and A. Baldi. 2001. Effects of vitamin $\mathrm{E}$ on urokinase-plasminogen activator receptor expression by bovine neutrophils. Am. J. Vet. Res. 62:1934-1938.

Roth, J. A., D. E. Frank, P. Weighner, and M. Weighner. 2001. Enhancement of neutrophil function by ultrafiltered bovine whey. J. Dairy Sci. 84:824-829.

Roth, J. A., and M. L. Kaeberle. 1981a. Effects of in vivo dexamethasone administration on in vitro bovine polymorphonuclear leukocyte function. Infect. Immun. 33:434-441.

Roth, J. A., and M. L. Kaeberle. 1981b. Evaluation of bovine polymorphonuclear leukocyte function. Vet. Immunol. Immunopathol. $2: 157-174$.

Sander, A. K., M. Piechotta, G. Schlamberger, H. Bollwein, M. Kaske, A. Sipka, and H. J. Schuberth. 2011. Ex vivo phagocytic overall performance of neutrophilic granulocytes and the relation to plasma insulin-like growth factor-I concentrations in dairy cows during the transition period. J. Dairy Sci. 94:1762-1771.

Scaletti, R. W., and R. J. Harmon. 2012. Effect of dietary copper source on response to coliform mastitis in dairy cows. J. Dairy Sci. 95:654-662.

Sheldon, I. M., G. S. Lewis, S. LeBlanc, and R. O. Gilbert. 2006. Defining postpartum uterine disease in cattle. Theriogenology 65:1516-1530.

Smith, K. L., J. H. Harrison, D. D. Hancock, D. A. Todhunter, and H. R. Conrad. 1984. Effect of vitamin E and selenium supplementation on incidence of clinical mastitis and duration of clinical symptoms. J. Dairy Sci. 67:1293-1300.

Tan, X., W. W. Li, J. Guo, and J. Y. Zhou. 2012. Down-regulation of NOD1 in neutrophils of periparturient dairy cows. Vet. Immunol. Immunopathol. 150:133-139.

Waller, K. P. 2000. Mammary gland immunology around parturition. Influence of stress, nutrition and genetics. Adv. Exp. Med. Biol. 480:231-245.

White-Owen, C., J. W. Alexander, R. M. Sramkoski, and G. F. Babcock. 1992. Rapid whole-blood microassay using flow cytometry for measuring neutrophil phagocytosis. J. Clin. Microbiol. 30:2071-2076. 